Biological and Clinical Sciences Research Journal

ISSN: 2708-2261

www.bcsrj.com

DOI: https://doi.org/10.54112/bcsri.v2021i1.71

Biol. Clin. Sci. Res. J., Volume, 2020: 71

Review Article

\title{
BIOSYNTHESIS OF POLY (HYDROXYALKANOATES)
}

\section{WAHEED M, MUBEEN B, SARWAR M, *HAFEEZ MM, ALI Q}

\author{
Institute of Molecular Biology and Biotechnology, The University of Lahore, Lahore, Pakistan \\ Corresponding author email: mansoorhafeez140@gmail.com
}

(Received, $26^{\text {th }}$ November 2020, Revised $18^{\text {th }}$ May 2021, Published $28^{\text {th }}$ May 2021)

\begin{abstract}
Bioplastics are biodegradable polymers that are made by bacterial cells, whose molecules have biochemical properties similar to petrochemical polymers as they are concentrated inside intracellular granules as a carbon and energy sources, and which then degrade in the environment as they get exposed to light. Bioplastics have desirable biodegradable and renewable qualities, sustainable qualities as well as alternatives to petroleumbased plastics, and is used due to much of its biodegradability and durability. Due to their vast usefulness, Poly Hydroxy Alkanoate (PHAs) and their derivatives are used in many different sectors, PHAs are the most biodegradable bioplastics found throughout the world. These polymers are generated by microorganisms through metabolic pathways that start with hydroxy-acyl-A and end with different types of acyl-A. Bioplastic polymers have chemical characteristics that differ in structural and physical properties which also differ due to the source of their polymerization microorganisms.
\end{abstract}

Keywords: PHAs, Bioplastics, Poly Hydroxy Alkanoate, biodegradable, polymers

\section{Introduction}

With increasing of the human population, earth's own biomass, as well as that of flora and fauna, the capacity to take care of human life is diminished. As a result, environmental degradation has become a significant problem for both human and all other organisms (Iles and Martin, 2013). Many nonbiodegradable materials are needed in order to sustain human life: Plastic, which is particularly in our atmosphere, is polluted with toxic chemicals, is required. Over the polyethylene is first break down into polyethyene which, with the help of some chemicals, and then poly (the degradation products) continues for approximately 1000 years as the resultant polyene (name for polyethylene after it has degraded). Using polycarbonate as another polymer instead of an additive (Brodin et al., 2017; Yamane, 1992), colouring agents, as well as some kind of polymers may have the final product to be noisomorphic to the original one because the plastic is decomposed to monomers during the recycling process. As a result of thinning of the ozone layer and increased greenhouse gas entrapment, the temperature of the Earth's surface increases. There are millions of marine animals and thousands of birds and other animal species which die each year as a result of plastic pollution. According to the United Nations Environment Programme, there are 46,000 bits of plastic debris in every square mile of water; the world's oceans have 125 million cubic miles of plastic litter (Adams et al., 2016; Boons et al., 2013). Animal waste may get wrapped up in these plastic items, causing blockage in the intestines, and as a result, the animals starve to death. Birds and other sea creatures get caught in plastic bags and drown or are unable to fly due to this particular piece of plastic eventually choking them to death. Approximately $21 \%$ of packaging products, glass, tin plate, and plastic (all of these materials are) and their recycling has to be created or reprocessed in order to make the beverage bottles they are made out of more ecofriendly, and the next decade's industrial profits. The revenue estimates for bioplastic claims that it will earn $30 \%$ of the market by 2030, if things keep going the way they are now (Brodin et al., 2017; Geissdoerfer et al., 2016).

Artificially manufactured polymers include polymers derived from petro-petrochemicals are not only nonbiodegradable, but also environmentally dangerous and suspect by non-biodegradable, or environmentally questionable polymers. Cleaning products made from biodegradable material market share of $60 \%$ of all biodegradable materials in Europe, Japan has also been working with bioplastics to produce biocomposite for electronics and vehicles (Brodin et al., 2017; Kusi-Sarpong et al., 2019). In light of their discovery of environmentally benign substitutes for polyester that do not compete with food crops for resources, as well as the fact that the majority of polyester can be produced and used more resourcefully nowadays. The aquatic or terrestrial

[Citation: Waheed, M., Mubeen, B., Sarwar, M., Hafeez, M.M., Ali, Q. (2021). Biosynthesis of poly (hydroxy alkanoates. Biol. Clin. Sci. Res. J., 2021: 71. doi: https://doi.org/10.54112/bcsrj.v2021i1.71] 
creatures can be harmed by improperly disposed chemicals which can end up with contaminated effects of petro-chemicals (Brockhaus et al., 2016; Neutzling et al., 2018). Bioplastics are a new family of bio-based, bio-degradable plastics with unique properties. For example, bio-based encompasses biosourced or biologically-derived materials. Alternative to synthetic plastic, it can be degradable by different microbes, including methanogens, $\mathrm{CO}_{2}$, and $\mathrm{H}_{2}$, which results in the release of the energy molecule carbon, $\mathrm{CO}_{2}$, as well as biomass. Typically, petroleum-based plastics (like polyvinyl chloride) are resistant to degradation because they have low biodegradation rates, making them persistent in the atmosphere for a very long time (Aminabhavi et al., 1990; Avella et al., 2005). As a result of the emission of $\mathrm{CO}_{2}$ due to use of high levels of fuel, this can be reduced by the use of Bioplastic.

The PHAs are the most widely derived biobiotics of the more abundant polyhydroxyalkanoates (PHAs, Poly Hydroxy Butyrate (PHBs), and their derivatives (e.g. Pomeroliproides). However, there are other kinds of polyesters formed by microorganisms. Most of the genes and enzymes used in the development of polyhydroxybutyrate/polypeptide acids would likely be similar, but there are no current applications for this biosynthetic group of compounds in industry (It will only be defined as long-chain/short-chain PHBs and PHAs.) Polyhydroxyalkanoates (PHA), polylactide (PLA), poly(p-caprolone) (P-E), poly(pdol) (P-X), and poly(p- succinate) are currently being studied for their various applications. Aside from the degradable polymers, PHAs are a family of polymers that is a younger member of, they have notable potential future value (which may result in) due to their attributes. There has worked on PHAs extensive study is going on, but tremendous efforts are being focused on lowering the cost (De Schryver et al., 2008; Salehizadeh and Van Loosdrecht, 2004). It is possible to manufacture large quantities of good substrate quickly and densely using recombinant microorganisms, which allow microorganism to have an intense PHAs formation and fit near packing (Verlinden et al., 2007). The costs can be lowered by implementing an effective fermentation methods (Anjum et al., 2016; Lee et al., 2014), as well as recovery techniques (Kourmentza et al., 2017).

\section{What is PHAs}

Many species exist because of adverse conditions to allow for their survival in harsher environments (Singh Saharan et al., 2014). According to common belief, PHA is biopolymers because of their biodegradability, and that is why they are typically called polyhydroxy acids (Kourmentza et al., 2017). Bio-based polyesters, which use Rhydrazine acid as a recurring unit, belong to a class of thermoplastics that includes Rhs (TPLA) polyesters. Although some groups of microorganisms work in media with insufficient oxygen, nitrogen, or $\mathrm{pH}$, there is always enough in there to feed the other ones, there are always a large number of nutrients in a surplus to allow for expansion. Biofabsorbates can be saved for use in later in making collagen as well as reducing carbon in stored away (Kumar et al., 2018; Obruca et al., 2020). When PHAs are put into a low-nutrient media, the microbes start to feed on the stored phytate, thereby generating carbon dioxide $\left(\mathrm{CO}_{2}\right)$ as a nutrient (Gedikli et al., 2019; Kumar et al., 2020b). The polyhydroxybutyrate (PHB) was discovered by Maurice Lemoigne in 1926, and researchers have since characterized it as the internal granules of $B$. megaterium (pluridyroxybacterium) (Lemoigne, 1926). contains microbial consort which together can raise PHB monomers to the level of 3hydroxybutyrate (3-hydroxybutyryl), however, 3hydroxybutyhxe can be regarded as a relatively insignificant secondary metabolite, representing no more than $1 \%$ of the overall sludge constituents, as per literature (Gonzalez et al., 2020; Kumar et al., 2019). An approximate estimate, given that there are approximately 150 carbon monomers with diverse structures that have different carbon chain lengths, is that unsaturated PHAs can comprise approximately 65 percent of this amount. There are over 90 microbe genera that are able to pick up PHAs intra-containing inside the cell cultures are examined (Gonzalez et al., 2020; Sathicq et al., 2021). Under conditions of nutrient stress, the bacterial population can be divided into two distinct groups: one that grows and the other that doesn't. Bacteria belonging to the "prime"like Ralstonia Pseudomonas need small nutrient precursors like phosphorous $(\mathrm{P})$ but can't biosynthesize PHAs (phosphate analogues) during their growth phases" (Kouřilová et al., 2021). PHAs accumulate by the second group of bacteria (e.g., Alcaligenes, Azotobacter, mutant strain of Escheria, and recombinant Escheria colony) aren't hindered by nutrient supply; they continue to accumulate when the limiting nutrient is at this point, but $\mathrm{PH}$ is scarce in their growth phase

Structural classification, diversity, and properties of PHAs

Vizal types (at varying rates) and/ stages of their development: Initially, Rhydroxy acid levels (All Types and Stages of RhyDNA) are equal, but as development proceeds, different Rhydanolic formulas emerge (Table 1). Under the assumption of the structural and number of carbon atoms, PHAs are classified into three categories: medium chain (m), short chain (sc), and long chain (Kunasundari and 
Sudesh, 2011). As either of these substances display homotrimer (straight chain), oligomer (chain of monomers) or heterotrimer (chain of oligomers) molecular configurations (Kalia, 2016; Kourmentza et al., 2017). Inorganic polyesters, poly(3hydroxybutyrate), poly(3-hydroxyisobutiryl), poly(4hydroxybutyrate), and poly(4-4-4-hydroxybutyrate) are 3E5 and poly(3), respectively. Also included are poly(3-hydroxy) and poly(4-1-1 hydroxybutyr), poly(4-3hydroxyut-4) or 4-4-hyd) poly(3)1-4) of poly(3-hydroxy) (3- hydroxy)) (3HB-co3HV). Carbon-chain poly(methylhydroxyalkanoate) polymers have 614 carbons. heteropolymers, which are formed from (Raza et al., 2018) polysaccharide $\mathrm{HO}$ and heterolysate and polyglycolate $\mathrm{PCOO}, \mathrm{HO}$ polyglykate and $\mathrm{PO}$ polysaccharide, which have polysaccharide and poly glykols inside them respectively (Kourmentza et al., 2017; Webb et al., 2013). They occupy more than 14 carbon atoms within the polymeric chain of PHA molecules, making them nonlyogenic (Kourmentza et al., 2017). PHAs are generated solely by PHA synthase, which has a very narrow substrate specificity and broadens the output range of substrate range. With a chain of up to six carbons, 3-hydroxyisobutamide cannot be linked to PHAs; as a result, the synthesis of PHA does not take place (Koller, 2018).

\section{Inherent properties of PHAs}

Differently weighted PHA molecules lead to differential properties in the polyhydroxy acids (PHAs), which in turn causes different chemical properties in polymeric polyols (polyols). As anion capability for incorporating lots of gas into polypropylene, while resisting moisture, is strongly believed to be essential in order to have favourable long-term performance (Koller, 2018; Kourmentza et al., 2018). Polymers can be seen as a result of water solubility and hydrolytic degradation's effect on biodegradation, as hydrolysis takes place under water and the presence of reduced atmospheric oxygen (while biodegradation happens in the absence of water) (Hatti-Kaul et al., 2020). Often means that they are biodegradable, biodegradable, and have the properties of a needle-like crystal (Hatti-Kaul et al., 2020). The chemical structure of polymers is highly chiral (flavour molecules are primarily determined by the kind of microorganisms, environmental conditions, and the relative chemical composition of the substrates that they prefer), and thus biodegradability is substantially dependent on these factors (all microbes produce PHA depolymerases and hydrolases different (Burniol-Figols et al., 2018). Given a serious shortfall of food and also estimates of an urgent need of thirty-two million people in food access to food by 2018, the need for land area expansions in African agriculture to accommodate additional agriculture to alleviate hunger and feed an estimated additional forty-two million, the inhabitants in Africa, an urgent action plan of producing an additional thirty-two million pounds of food by 2018 is needed. One may presume that the more urgent plan is Boyin et al., suggestion to develop more land in African agriculture to accommodate additional agriculture in order to feed an estimated forty million more individuals as foodneedy people, meaning one must accept the Boyin's proposal to act quickly on urgent issues, as the large expansions in African agriculture which as means. The other properties of PHA polymers are closely related to their biopolymeric and monomeric composition (Manavitehrani et al., 2016).

\section{Biodegradability of PHAs}

The ability to quickly break down into simple constituents when placed in a biological environments (reacting strongly with water) is one of the advantages in consideration (Burniol-Figols et al., 2018; Hatti-Kaul et al., 2020). That have previously been shown to be generated by bacteria in the phage polymerase bacteria which help the depolymerization and polylolysis of polymers, is called the PHAspecific and PA specific enzymes, respectively (Gonzalez et al., 2020; Kourmentza et al., 2018). Variability of polymeric chains is mainly influenced by the nature of the chemical composition and the crystallinity of the polymers; polymers have different properties and crystalline as well as physical properties that also play a role in the PHA and polymeric chain's length. Most types of bacteria, and other living organisms, exhibit an increased risk of enzymatic degradation when exposed to different sources of fluctuating stress conditions (pathogens, growth factors, dietary supplements, drugs, and chemicals). Besides the usual sources of light and chemical constituents, temperature, humidity, $\mathrm{pH}$, and oxygen are also influence the polymers are crucial for the synthesis of polymers manufacturing (Koller, 2018; Kumar et al., 2019).

\section{Life cycle and renewability of PHAs}

Our ability to renew our capital enables the production of PHA (Obruca et al., 2020; Verlinden et al., 2007). Specifically, PHAs are synthesised using agriculture as a carbon and energy source, and they biodegrade (Ed. 2). Therefore, PHA production is as essential and as much in demand as it is obtained from renewable sources (Verlinden et al., 2007). Formal lifestyle analysis (LCA) that begins at birth and includes everything from the development of green bioplastics to the landfill. The various studies found in regard to renewable polymers to have an environmental effect (Kourmentza et al., 2017). LCA 
data indicates that bioplastics processing has minimal environmental impact as opposed to other environmental indicators. However, synthetic plastic is more quickly biodegradable than others (Webb et al., 2013). In order to integrate all environmental measurements efficiently, an index must be created. It is also, however, PHA has advanced to the point of industrial scale and mass production has been developed (Kumar et al., 2020b; Yamane, 1992).

Microorganisms

Table 1. microganisms and sources of carbons for PHAs production

\begin{tabular}{|c|c|c|}
\hline Bacterial strain (s) & Carbon source (s) & $\begin{array}{l}\text { Polymer }(s) \\
\text { produced }\end{array}$ \\
\hline Aeromonas hydrophila & oleic acid, Lauric acid & mcl-PHAs \\
\hline Alcaligenes latus & soy waste, Malt, milk waste, sesame oil, vinegar waste & PHB \\
\hline Bacillus cereus & Glucose, sugarbeet molasses, $\varepsilon$-caprolactone & PHB, terpolymer \\
\hline Bacillus spp. & $\begin{array}{l}\text { alkanoates, Nutrient broth, soy molasses glucose, } \\
\varepsilon \text {-caprolactone }\end{array}$ & $\begin{array}{l}\text { PHB, PHBV, } \\
\text { copolymers }\end{array}$ \\
\hline Burkholderia sacchari sp. nov. & $\begin{array}{l}\text { Adonitol, arabitol, arabinose, fructose, cellobiose, lactose, } \\
\text { fucose, rhamnose, melibiose, raffinose, sorbitol, maltose, } \\
\text { trehalose, sucrose, xylitol }\end{array}$ & PHB, PHBV \\
\hline Burkholderia cepacia & $\begin{array}{l}\text { palm stearin, Palm olein, oleic acid, crude palm oil, xylose, } \\
\text { sugarbeet molasses levulinic acid, palm kernel oil }\end{array}$ & PHB, PHBV \\
\hline Caulobacter crescentus & Caulobacter medium, glucose & PHB \\
\hline Escherichia coli mutants & Glucose, glycerol, palm oil, ethanol, sucrose, molasses & (UHMW)PHB \\
\hline Halomonas boliviensis & Starch hydolysate, maltose, maltotetraose and maltohexaose & PHB \\
\hline Legionella pneumophila & Nutrient broth & PHB \\
\hline Methylocystis sp. & Methane & PHB \\
\hline Microlunatus phosphovorus & Glucose, acetate & PHB \\
\hline Pseudomonas aeruginosa & $\begin{array}{l}\text { technical oleic acid, Glucose, waste free frying oil, waste } \\
\text { free fatty acids }\end{array}$ & mcl-PHAs \\
\hline Pseudomonas oleovorans & Octanoic acid & mcl-PHAs \\
\hline Pseudomonas putida & Glucose, undecenoic acid, octanoic acid & mcl-PHAs \\
\hline Pseudomonas putida, $P$. & aromatic monomers, Glucose & aromatic \\
\hline fluorescens, $P$. jessenii & & polymers \\
\hline Pseudomonas stutzeri & \multirow{2}{*}{$\begin{array}{l}\text { soybean oil, Glucose, alkanoates, alcohols } \\
\text { sucrose, Glucose, galactose, trehalose, xylose, sugar beet } \\
\text { molasses, mannitol, raffinose, dextrose, lactose, maltose, } \\
\text { pyruvate, whey }\end{array}$} & mcl-PHAs \\
\hline $\begin{array}{l}\text { Rhizobium meliloti, } R \text {. viciae, } \\
\text { Bradyrhizobium japonicum }\end{array}$ & & PHB \\
\hline Rhodopseudomonas palustris & $\begin{array}{l}\text { malate, Acetate, fumarate, propionate, succinate, gluconate, } \\
\text { malonate, butyrate, citrate, glycerol, }\end{array}$ & $\mathrm{PHB}, \mathrm{PHBV}$ \\
\hline Spirulina & \multirow[t]{2}{*}{ Carbon dioxide } & PHB \\
\hline platensis (cyanobacterium) & & \\
\hline Staphylococcus epidermidis & vinegar waste, sesame oil, Malt, milk waste, soy waste & PHB \\
\hline Cupriavidus necator & $\begin{array}{l}\text { Glucose, fructose, sucrose, valerate, octanoate, soybean oil, } \\
\text { lactic acid }\end{array}$ & $\begin{array}{l}\text { PHB, } \\
\text { copolymers }\end{array}$ \\
\hline Cupriavidus necator $\mathrm{H} 16$ & Hydrogen, carbon dioxide & PHB \\
\hline $\begin{array}{l}\text { Person bacterial system } \\
\text { development } \\
\text { Depending on the culture condit } \\
\text { two distinct groups: long-tern } \\
\text { several months) and short-term } \\
\text { generated by bacteria in an in } \\
\text { solution in a nutrient def }\end{array}$ & \multicolumn{2}{|c|}{$\begin{array}{l}\text { preconditioned (or prepared) medium. Often referred } \\
\text { to as the Rhodopolankrus philippinearum, but are } \\
\text { grouped separately with Methylobacterium } \\
\text { organophilum are Rhodobacter and Cupriopsis } \\
\text { phage. Once bacteria in the second group have } \\
\text { multiplied in the cultivation medium, PHAs are } \\
\text { formed in the final culture as well. Often referred to } \\
\text { as Alcaligenes, these types of bacteria include both }\end{array}$} \\
\hline
\end{tabular}

PHAs are made by a variety of viral cultures. The most studied species is $C$. Cupriavidus necator (formerly known as Ralstonia eutropha or Alcaligenes eutrophus) (Venkatachalam and Palaniswamy, 2020). Billillus sp., Pseudomonas spp., Rhodopseudomonas palustris, Aeromonas hydrophila, Burkholderia sacchari, Escherichia coli, Halomonas boliviensis and Alcaligenes sp., are among the microorganisms that have recently been examined.

[Citation: Waheed, M., Mubeen, B., Sarwar, M., Hafeez, M.M., Ali, Q. (2021). Biosynthesis of poly (hydroxy alkanoates. Biol. Clin. Sci. Res. J., 2021: 71. doi: https://doi.org/10.54112/bcsrj.v2021i1.71] 
recombinant $E$. coli that have the genes which allow them to synthesise PHA and AlCAL (Ciesielski et al., 2006; Kumar et al., 2020a). Many microorganisms, in solution are able to synthesise vast quantities of $\mathrm{P}(3 \mathrm{HB})$ using a variety of simple carbon substrates, including glucose, lactic acid and citric acid (Mascarenhas and Aruna, 2017). We can derive about $80 \%$ of dry weight $\mathrm{P}(3 \mathrm{HB})$ from olive oil, corn oil, and palm oil, respectively, through an aerobic granulation process (Verlinden et al., 2007). Although Rhodopseudomonas cannot use hydrogen sulphide as a carbon source, Methylobacterium organophilum produces PHAs using methanol (3HBco-3HV). The two bacteria that use malate as a carbon source are thus classed as non-sulfurantis isopeptical Bacteria: Rhodospirillum rubrum and Rhodobacter are non-sulphuriant organisms that use malate to produce copolymer, which is a polymer derived from acetic acid and n-alkanoic acid (Chen, 2009).

Although Alcaligenes use molasses, sucrose, and glucose as a carbon source are best able to generate PHAs, Alcaligenes have been observed to do so. Studies revealed that treatment with lactate was effective in yielding different nitrogen sources (NH4 $+\&$ ammonium sulphate) and were able to result in PHAs that had ammonium chloride and ammonium as constituents. While both of these fertilizers were tried, they could not maintain the continuous output of PHA in the organism (Chanprateep, 2010). It is effective at a temperature of $35^{\circ} \mathrm{C}$ and lowers the cooling requirements during fermentation, enabling the production of $\mathrm{P}(3 \mathrm{HB})$ at a lower cost. Alternatively, the organism can be fed a medium supplemented to reach the maximum amount of biomass and growth of approximately double what occurs naturally. Using recombinant organisms to increase polyphosphagenic acid synthesis has been shown to be useful. Among all, E. coli supports the growth of PHA development because of these bacteria are not known to be bacteriophilic. Its economical purification technology makes it possible for the sugar cane to achieve a high cell concentration from different carbon sources and also gives it a cost advantage to working with whey proteins, and is less difficult for the E. coli to synthesize (Laycock et al., 2013; Luckachan and Pillai, 2011).

\section{Renewable nature and life cycle}

PHAs are generated using biological processes and require more resources (Anjum et al., 2016). Fermentation process PHAs are made from agricultural feeds such as sugars and fatty acids, which provide both carbon and energy (Tan et al., 2014). PHA synthesis and degradation are fully carbon-cycle compatible. PHAs have attracted a lot of attention because they depend on renewable energy rather than energy sources (Lu et al., 2009). While petrochemical plastics processing has progressed, the fermentation process for preparing PHAs has yet to be refined (Singh et al., 2009). PHAs are thermoplastics that are semi, biocompatible, and biodegradable and are manufactured from renewable resources. They are porous compounds that are highly reactive, piezoelectric, carboxyl groups regular in repeating groups, highly polymerized, and insoluble in water. Because of their unique characteristics, they have a variety of uses. These were mainly used in package packaging films, paper coatings, and bags. Thermoplastic uses include cosmetic packaging, diapers, razors, spoons, feminine care goods. Longterm dosages of medicines, herbicides, poisons, hormones, and narcotics could be distributed in biodegradable carriers. Because of their piezoelectric Medical and pharmaceutical applications, on the other hand, are limited due to slow oxidation and high hydraulic stability in sterile tissues (Rydz et al., 2015; Zhang et al., 2018).

\section{Conclusion}

Because commercial bioplastic manufacturing is currently costly, the price of making them is unlikely to decline, there is a significant investment required to meet this requirement. More research into mixed cultures, effective lower production costs significantly. Bioplastics are currently used less frequently in medical, food, and other consumable packaging. However, due to the environmental problems faced by traditional petroleum hydrocarbon derived plastics, it will be phased out in the near future. Because of their organic nature and biodegradability, PHAs would be a suitable resource to replace synthetic plastics in many applications. Related genetic and metabolic engineering techniques can be used to create various polyesters with plastic properties. Finally, bioplastics have a bright future ahead of them due to their unique properties and broad range of biotechnological applications.

\section{Conflict of interest}

The authors declared absence of conflict of interest.

\section{References}

Adams, R., Jeanrenaud, S., Bessant, J., Denyer, D., and Overy, P. (2016). Sustainability-oriented innovation: A systematic review. International Journal of Management Reviews 18, 180-205.

Aminabhavi, T., Balundgi, R., and Cassidy, P. (1990). A review on biodegradable plastics. Polymer-Plastics Technology and Engineering 29, 235-262.

Anjum, A., Zuber, M., Zia, K. M., Noreen, A., Anjum, M. N., and Tabasum, S. (2016).

[Citation: Waheed, M., Mubeen, B., Sarwar, M., Hafeez, M.M., Ali, Q. (2021). Biosynthesis of poly (hydroxy alkanoates. Biol. Clin. Sci. Res. J., 2021: 71. doi: https://doi.org/10.54112/bcsrj.v2021i1.71] 
Microbial production of polyhydroxyalkanoates (PHAs) and its copolymers: a review of recent advancements. International journal of biological macromolecules 89, 161-174.

Avella, M., De Vlieger, J. J., Errico, M. E., Fischer, S., Vacca, P., and Volpe, M. G. (2005). Biodegradable starch/clay nanocomposite films for food packaging applications. Food chemistry 93, 467-474.

Boons, F., Montalvo, C., Quist, J., and Wagner, M. (2013). Sustainable innovation, business models and economic performance: an overview. Journal of Cleaner Production 45, $1-8$.

Brockhaus, S., Petersen, M., and Kersten, W. (2016). A crossroads for bioplastics: exploring product developers' challenges to move beyond petroleum-based plastics. Journal of Cleaner Production 127, 84-95.

Brodin, M., Vallejos, M., Opedal, M. T., Area, M. C., and Chinga-Carrasco, G. (2017). Lignocellulosics as sustainable resources for production of bioplastics-A review. Journal of Cleaner Production 162, 646-664.

Burniol-Figols, A., Varrone, C., Le, S. B., Daugaard, A. E., Skiadas, I. V., and Gavala, H. N. (2018). Combined polyhydroxyalkanoates (PHA) and 1, 3-propanediol production from crude glycerol: Selective conversion of volatile fatty acids into PHA by mixed microbial consortia. Water research 136, 180-191.

Chanprateep, S. (2010). Current trends in biodegradable polyhydroxyalkanoates. Journal of bioscience and bioengineering 110, 621632.

Chen, G.-Q. (2009). A microbial polyhydroxyalkanoates (PHA) based bio-and materials industry. Chemical Society Reviews 38, 2434-2446.

Ciesielski, S., Cydzik-Kwiatkowska, A., Pokoj, T., and Klimiuk, E. (2006). Molecular detection and diversity of medium-chain-length polyhydroxyalkanoates-producing bacteria enriched from activated sludge. Journal of applied microbiology 101, 190-199.

De Schryver, P., Crab, R., Defoirdt, T., Boon, N., and Verstraete, W. (2008). The basics of bio-flocs technology: the added value for aquaculture. Aquaculture 277, 125-137.

Gedikli, S., Çelik, P. A., Demirbilek, M., Mutlu, M. B., Denkbaş, E. B., and Çabuk, A. (2019). Experimental exploration of thermostable poly ( $\beta$-hydroxybutyrates) by Geobacillus kaustophilus using Box-Behnken Design.
Journal of Polymers and the Environment 27, 245-255.

Geissdoerfer, M., Bocken, N. M., and Hultink, E. J. (2016). Design thinking to enhance the sustainable business modelling process-A workshop based on a value mapping process. Journal of Cleaner Production 135, 12181232.

Gonzalez, K., Navia, R., Liu, S., and Cea, M. (2020). Biological Approaches in Polyhydroxyalkanoates Recovery. Current Microbiology, 1-10.

Hatti-Kaul, R., Nilsson, L. J., Zhang, B., Rehnberg, N., and Lundmark, S. (2020). Designing biobased recyclable polymers for plastics. Trends in biotechnology 38, 50-67.

Iles, A., and Martin, A. N. (2013). Expanding bioplastics production: sustainable business innovation in the chemical industry. Journal of Cleaner Production 45, 38-49.

Koller, M. (2018). Biodegradable and biocompatible polyhydroxy-alkanoates (PHA): Auspicious microbial macromolecules for pharmaceutical and therapeutic applications. Molecules 23, 362.

Koư̌ilová, X., Schwarzerová, J., Pernicová, I., Sedlář, K., Mrázová, K., Krzyžánek, V., Nebesářová, J., and Obruča, S. (2021). The First Insight into Polyhydroxyalkanoates Accumulation in Multi-Extremophilic Rubrobacter xylanophilus and Rubrobacter spartanus. Microorganisms 9, 909.

Kourmentza, C., Costa, J., Azevedo, Z., Servin, C., Grandfils, C., De Freitas, V., and Reis, M. (2018). Burkholderia thailandensis as a microbial cell factory for the bioconversion of used cooking oil to polyhydroxyalkanoates and rhamnolipids. Bioresource technology 247, 829-837.

Kourmentza, C., Plácido, J., Venetsaneas, N., Burniol-Figols, A., Varrone, C., Gavala, H. N., and Reis, M. A. (2017). Recent advances and challenges towards sustainable polyhydroxyalkanoate (PHA) production. Bioengineering 4, 55.

Kumar, M., Rathour, R., Singh, R., Sun, Y., Pandey, A., Gnansounou, E., Lin, K.-Y. A., Tsang, D. C., and Thakur, I. S. (2020a). Bacterial polyhydroxyalkanoates: Opportunities, challenges, and prospects. Journal of Cleaner Production, 121500.

Kumar, V., Kumar, S., Darnal, S., Patial, V., Singh, A., Thakur, V., Kumar, S., and Singh, D. (2019). Optimized chromogenic dyes-based identification and quantitative evaluation of

[Citation: Waheed, M., Mubeen, B., Sarwar, M., Hafeez, M.M., Ali, Q. (2021). Biosynthesis of poly (hydroxy alkanoates. Biol. Clin. Sci. Res. J., 2021: 71. doi: https://doi.org/10.54112/bcsrj.v2021i1.71] 
bacterial 1-asparaginase with low/no glutaminase activity bioprospected from pristine niches in Indian trans-Himalaya. 3 Biotech 9, 1-9.

Kumar, V., Kumar, S., and Singh, D. (2020b). Microbial polyhydroxyalkanoates from extreme niches: Bioprospection status, opportunities and challenges. International journal of biological macromolecules 147, 1255-1267.

Kumar, V., Thakur, V., Kumar, S., and Singh, D. (2018). Bioplastic reservoir of diverse bacterial communities revealed along altitude gradient of Pangi-Chamba trans-Himalayan region. FEMS microbiology letters 365, fny 144 .

Kunasundari, B., and Sudesh, K. (2011). Isolation and recovery of microbial polyhydroxyalkanoates. Express Polymer Letters 5.

Kusi-Sarpong, S., Gupta, H., and Sarkis, J. (2019). A supply chain sustainability innovation framework and evaluation methodology. International Journal of Production Research 57, 1990-2008.

Laycock, B., Halley, P., Pratt, S., Werker, A., and Lant, P. (2013). The chemomechanical properties of microbial polyhydroxyalkanoates. Progress in polymer science 38, 536-583.

Lee, W. S., Chua, A. S. M., Yeoh, H. K., and Ngoh, G. C. (2014). A review of the production and applications of waste-derived volatile fatty acids. Chemical Engineering Journal 235, 8399.

Lemoigne, M. (1926). Produits de deshydration et de polymerisation de l'acide $\beta=$ oxybutyrique. Bull. Soc. Chim. Biol. 8, 770-782.

Lu, J., Tappel, R. C., and Nomura, C. T. (2009). Mini-review: biosynthesis of poly (hydroxyalkanoates). Journal of Macromolecular Science ${ }^{\circledR}$, Part C: Polymer Reviews 49, 226-248.

Luckachan, G. E., and Pillai, C. (2011). Biodegradable polymers-a review on recent trends and emerging perspectives. Journal of Polymers and the Environment 19, 637-676.

Manavitehrani, I., Fathi, A., Badr, H., Daly, S., Negahi Shirazi, A., and Dehghani, F. (2016). Biomedical applications of biodegradable polyesters. Polymers 8, 20.

Mascarenhas, J., and Aruna, K. (2017). Screening of polyhydroxyalkonates (PHA) accumulating bacteria from diverse habitats. J Global Biosci $6,4835-48$.
Neutzling, D. M., Land, A., Seuring, S., and do Nascimento, L. F. M. (2018). Linking sustainability-oriented innovation to supply chain relationship integration. Journal of Cleaner Production 172, 3448-3458.

Obruca, S., Sedlacek, P., Slaninova, E., Fritz, I., Daffert, C., Meixner, K., Sedrlova, Z., and Koller, M. (2020). Novel unexpected functions of PHA granules. Applied microbiology and biotechnology 104, 4795-4810.

Raza, Z. A., Abid, S., and Banat, I. M. (2018). Polyhydroxyalkanoates: Characteristics, production, recent developments and applications. International Biodeterioration \& Biodegradation 126, 45-56.

Rydz, J., Sikorska, W., Kyulavska, M., and Christova, D. (2015). Polyester-based (bio) degradable polymers as environmentally friendly materials for sustainable development. International journal of molecular sciences $\mathbf{1 6}$, 564-596.

Salehizadeh, H., and Van Loosdrecht, M. (2004). Production of polyhydroxyalkanoates by mixed culture: recent trends and biotechnological importance. Biotechnology advances 22, 261-279.

Sathicq, M. B., Sabatino, R., Corno, G., and Di Cesare, A. (2021). Are microplastic particles a hotspot for the spread and the persistence of antibiotic resistance in aquatic systems? Environmental Pollution, 116896.

Singh, M., Patel, S. K., and Kalia, V. C. (2009). Bacillus subtilis as potential producer for polyhydroxyalkanoates. Microbial cell factories 8, 1-11.

Singh Saharan, B., Grewal, A., and Kumar, P. (2014). Biotechnological production of polyhydroxyalkanoates: a review on trends and latest developments. Chinese Journal of Biology 2014.

Tan, G.-Y. A., Chen, C.-L., Li, L., Ge, L., Wang, L., Razaad, I. M. N., Li, Y., Zhao, L., Mo, Y., and Wang, J.-Y. (2014). Start a research on biopolymer polyhydroxyalkanoate (PHA): a review. Polymers 6, 706-754.

Venkatachalam, H., and Palaniswamy, R. (2020). BIOPLASTIC WORLD: A REVIEW. Journal of Advanced Scientific Research 11.

Verlinden, R. A., Hill, D. J., Kenward, M., Williams, C. D., and Radecka, I. (2007). Bacterial synthesis of biodegradable polyhydroxyalkanoates. Journal of applied microbiology 102, 1437-1449.

Webb, H. K., Arnott, J., Crawford, R. J., and Ivanova, E. P. (2013). Plastic degradation and

[Citation: Waheed, M., Mubeen, B., Sarwar, M., Hafeez, M.M., Ali, Q. (2021). Biosynthesis of poly (hydroxy alkanoates. Biol. Clin. Sci. Res. J., 2021: 71. doi: https://doi.org/10.54112/bcsrj.v2021i1.71] 
its environmental implications with special reference to poly (ethylene terephthalate). Polymers 5, 1-18.

Yamane, T. (1992). Cultivation engineering of microbial bioplastics production. FEMS microbiology reviews $9,257-264$.

Zhang, X., Fevre, M., Jones, G. O., and Waymouth, R. M. (2018). Catalysis as an enabling science for sustainable polymers. Chemical reviews 118, 839-885.

\section{(c) $(1)(9$}

Open Access This article is licensed under a Creative Commons Attribution 4.0 International License, which permits use, sharing, adaptation, distribution and reproduction in any medium or format, as long as you give appropriate credit to the original author(s) and the source, provide a link to the Creative Commons licence, and indicate if changes were made. The images or other third party material in this article are included in the article's Creative Commons licence, unless indicated otherwise in a credit line to the material. If material is not included in the article's Creative Commons licence and your intended use is not permitted by statutory regulation or exceeds the permitted use, you will need to obtain permission directly from the copyright holder. To view a copy of this licence, visit http://creativecommons.org/licen ses/by/4.0/.

(C) The Author(s) 2021

[Citation: Waheed, M., Mubeen, B., Sarwar, M., Hafeez, M.M., Ali, Q. (2021). Biosynthesis of poly (hydroxy alkanoates. Biol. Clin. Sci. Res. J., 2021: 71. doi: https://doi.org/10.54112/bcsrj.v2021i1.71] 